\title{
Chronic pain after breast surgery: incidence, associated factors, and impact on quality of life, an observational prospective study
}

Gianluca Villa ${ }^{1,2^{*}}$, Raffaele Mandarano ${ }^{1}$, Caterina Scirè-Calabrisotto ${ }^{1}$, Valeria Rizzelli ${ }^{1}$, Martina Del Duca ${ }^{1}$, Diego Pomarè Montin', Laura Paparella², A. Raffaele De Gaudio ${ }^{1,2}$ and Stefano Romagnoli, ${ }^{1,2}$

\begin{abstract}
Background: Chronic pain after breast surgery (CPBS) has a disabling impact on postoperative health status. Mainly because of the lack of a clear definition, inconsistency does exist in the literature concerning both the actual incidence and the risk factors associated to CPBS. The aim of this prospective, observational study is to describe the incidence of and risk factors for CPBS, according to the definition provided by the IASP taskforce. The impact of CPBS on patients' function and quality of life is also described.

Methods: Women aged 18+ undergoing oncological or reconstructive breast surgery from Jan until Apr 2018 at the Breast Unit of Careggi Hospital (Florence, Italy) were prospectively observed. Postoperative pain was measured at $0 \mathrm{~h}, 3 \mathrm{~h}, 6 \mathrm{~h}, 12 \mathrm{~h}, 24 \mathrm{~h}, 48 \mathrm{~h}$, and 3 months (CPBS) after surgery. Preoperative, intraoperative, and postoperative factors were compared in CPBS and No-CPBS groups through multivariate logistic regression analysis.

Results: Among the 307 patients considered in this study, the incidence of CPBS was 28\% [95\% Cl 23.1-33.4\%]. Results from the logistic regression analysis suggest that axillary surgery (OR $[95 \% \mathrm{Cl}], 2.99[1.13-7.87], p=0.03)$, preoperative use of pain medications (OR [95\% Cl], 2.04 [1.20-3.46], $p=0.01$ ), and higher dynamic NRS values at $6 \mathrm{~h}$ postoperatively (OR [95\% Cl], 1.28 [1.05-1.55], $p=0.01$ ) were all independent predictors for CPBS.

Conclusions: Chronic pain after breast surgery is a frequent complication. In our cohort, long-term use of analgesics for pre-existing chronic pain, axillary surgery, and higher dynamic NRS values at $6 \mathrm{~h}$ postoperatively were all factors associated with increased risk of developing CPBS. The possibility to early detect persistent pain, particularly in those patients at high risk for CPBS, might help physicians to more effectively prevent pain chronicisation.
\end{abstract}

Trial registration: ClinicalTrials.gov registration NCT04309929.

Keywords: IASP definition, Axillary surgery, Breast cancer, Numerical rating scale, Brief pain inventory questionnaire

\footnotetext{
* Correspondence: gianluca.villa@unifi.it

'Department of Health Sciences, Section of Anaesthesiology, Intensive Care and Pain Medicine, University of Florence, Viale Pieraccini, 6, 50139 Florence, Italy

${ }^{2}$ Department of Anaesthesia and Intensive Care, Azienda Ospedaliero

Universitaria Careggi, Largo Brambilla,3, Florence 50100, Italy
}

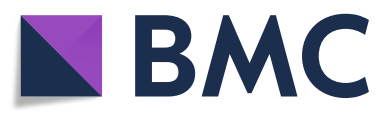

( The Author(s). 2021 Open Access This article is licensed under a Creative Commons Attribution 4.0 International License, which permits use, sharing, adaptation, distribution and reproduction in any medium or format, as long as you give appropriate credit to the original author(s) and the source, provide a link to the Creative Commons licence, and indicate if changes were made. The images or other third party material in this article are included in the article's Creative Commons licence, unless indicated otherwise in a credit line to the material. If material is not included in the article's Creative Commons licence and your intended use is not permitted by statutory regulation or exceeds the permitted use, you will need to obtain permission directly from the copyright holder. To view a copy of this licence, visit http://creativecommons.org/licenses/by/4.0/. The Creative Commons Public Domain Dedication waiver (http://creativecommons.org/publicdomain/zero/1.0/) applies to the data made available in this article, unless otherwise stated in a credit line to the data. 


\section{Background}

Chronic pain after breast surgery (CPBS) is a frequent condition associated with significant morbidity and/or debilitating complications (Odle 2014; Peuckmann et al. 2009). CPBS can range from mild to moderate, with pain lasting for months to years, and can have neuropathic characteristics such as burning, stabbing, pulling, hypoesthesia/anaesthesia, and phantom breast/nipple (Caffo et al. 2003; Jung et al. 2003). Chronic pain has a disabling impact on health status and negatively affects the quality of life of breast cancer survivors (Belfer et al. 2013), as it can affect sleep, work, activities of daily living, and interpersonal relationships (Miaskowski et al. 2012).

The pathophysiology of CPBS is extremely complex and not completely understood (Lavand'homme 2017). Several pathophysiological theories have been postulated to explain the development of chronic pain after surgery, including traumatic nerve injury, inflammation, and peripheral and central sensitisation (Urits et al. 2020). These mechanisms seem particularly pronounced in patients undergoing breast surgery. In particular, female gender seems to be associated with greater pain sensitivity and higher levels of acute and chronic postoperative pain compared to male gender (Deumens et al. 2013). Hormonal characteristics, as well as diverse immune and stress responses to surgery, have been advocated to explain these differences (Deumens et al. 2013). Furthermore, younger patients like those undergoing breast surgery are more prone to robust hormonal and neuroinflammatory responses (Deumens et al. 2013). Finally, breast surgery seems to be associated with a higher incidence and greater severity of nerve injuries compared with other surgical procedures. Because of the complex structure of the axillary and breast regions, nerve severance, compression, ischemia, stretching, and retraction during breast cancer operation, or from subsequent formation of a traumatic neuroma or scar tissue, unlikely preserve neural structures (Sarhadi et al. 1996). All these factors contribute to the higher prevalence of chronic pain in breast surgery patients (Deumens et al. 2013). Based on the pathophysiological mechanisms described above, some have suggested that a multimodal approach-involving, for instance, use of anti-inflammatory drugs (for preventing primary hyperalgesia) or locoregional anaesthesia (nerve blocks or epidural anaesthesia, for preventing secondary hyperalgesia and central nervous system sensitisation) - may limit the transition from acute to chronic pain (Urits et al. 2020).

Several efforts have been made to identify preoperative (Bell et al. 2014; Gartner et al. 2009; Mejdahl et al. 2013; Poleshuck et al. 2006; Spivey et al. 2018; Wang et al. 2018), intraoperative (Mejdahl et al. 2013; Spivey et al. 2018), and postoperative (Fassoulaki et al. 2009; Hamood et al. 2018; Schou Bredal et al. 2014; Wang et al. 2018) factors potentially associated with CPBS, including, but not limited to, young age, genetic features, chemotherapy, radiotherapy, or lymph node dissection. Nonetheless, results are inconsistent, and uncertainty does exist on the definition of those patients susceptible to CPBS. Interestingly, conflicting results are reported in the literature concerning the estimated incidence of CPBS. Although recognised as a frequent complication, the occurrence of CPBS varies across studies ranging from 25 to 60 (Gartner et al. 2009), mainly because of the lack of a clear definition, unequal follow-up time points, and case-mix heterogeneity (Brummett 2011). Only recently, the International Association for the Study of Pain (IASP) Taskforce for the Classification of Chronic Pain has provided a final, unambiguous definition for CPBS, defining it as "pain that develops or worsens after a surgical procedure in the breast area (anterolateral chest wall and, in some cases, the ipsilateral axillary region) and persists at 3 months after surgery" (Schug et al. 2019).

Taking into consideration this new and widely accepted definition, the aim of this prospective, observational study is to describe the incidence of and risk factors for CPBS in a cohort of female patients undergoing surgery for breast cancer. The intensity and impact of CPBS on patients' daily activities will also be described.

\section{Methods}

All adult (age $\geq 18$ years) female patients scheduled for breast surgery from Jan to Apr 2018 at the Breast Unit of Careggi Hospital, a large tertiary care teaching hospital in Florence, Italy, were prospectively observed. The study was approved by the Ethical Committee of Area Vasta Toscana Centro before enrolment of the first patient $\left(\mathrm{N}^{\circ}\right.$ OSS.16.246, clinicalTrials.gov registration NCT04309929). Each patient gave her consent for participation in this study and publication of the results. Participants were not compensated for their participation in the study.

According to local routine practice, all patients were preoperatively taught how to correctly identify and treat acute postoperative and chronic pain. In particular, the signs and symptoms associated with CPBS (e.g., burning, stabbing, pulling, hypoesthesia/anaesthesia, phantom breast/nipple), and the use of patient-controlled analgesia (PCA) and rescue analgesia were explained to all breast surgery candidates.

Each patient was prospectively observed during the entire perioperative period (from preoperative anaesthesia evaluation to postoperative and post hospital discharge). Demographic characteristics and comorbidities were recorded before surgery, as well as the presence of chronic pain and chronic use of analgesics. Intraoperative 
surgical and anaesthesiologic variables were prospectively recorded right after the surgical procedure. Finally, use of analgesic drugs was recorded at $0 \mathrm{~h}, 3 \mathrm{~h}, 6 \mathrm{~h}, 12 \mathrm{~h}$, $24 \mathrm{~h}$, and $48 \mathrm{~h}$ after surgery. Acute postoperative pain was assessed at the same time points using the numerical rating scale (NRS)-ranging from 0 (no pain) to 10 (worst pain) - both in resting conditions (static pain) and during active ipsilateral arm abduction or cough (dynamic pain). Each patient was re-evaluated at 3 months postoperatively for the presence of signs and symptoms of pain that develops or worsens in the breast area. Using a yes/no question, patients were asked to selfreport the presence of pain, and, if possible, evaluate its severity through a scale ranging from zero (no pain) to 10 (worst pain imaginable). According to the IASP definition (Schug et al. 2019), the presence of signs and symptoms of pain at 3 months was considered CPBS.

To reduce assessment biases, an anaesthesiologist not involved in the surgical procedure assessed pain both postoperatively and during follow-up. Preoperative, intraoperative, and postoperative variables statistically associated with CPBS were evaluated. Finally, we assessed pain intensity and pain interference with daily functions in patients with CPBS using the Italian validated version of the Brief Pain Inventory (BPI) questionnaire (Bonezzi et al. 2002; Daut et al. 1983). This is a multidimensional 10 -item questionnaire aimed at exploring the impact of pain on each item, with values ranging between 0 and 10 $(0=$ minimal impact, $10=$ invalidating impact $)$. Patients with missing preoperative, intraoperative, and postoperative data were excluded from the analysis.

\section{Statistical analysis}

According to data available in the literature (Vilholm et al. 2008), we calculated the sample size required to expect CPBS in $24 \%$ of the subjects included (CI 95\% interval width 0.1 ), with $90 \%$ statistical power and 0.05 level of significance.

Continuous variables are expressed as means \pm standard deviation or medians and interquartile range, according to data distribution (normality assessed through Shapiro-Wilk test). The CPBS and No-CPBS groups of patients were compared for statistical differences using the unpaired Student's $t$-test and the Wilcoxon's test for normally and not normally distributed variables, respectively. Categorical variables are expressed as a percentage; statistical differences between the two groups were evaluated through a Chi-square or Fisher's exact test. A multivariate logistic regression model was designed considering quantitative and qualitative variables significantly associated with CPBS in the univariate analysis ( $p$-value $<0.2)$. A backward selection procedure based on the AIC was used to select the variables in the final model. Results are expressed in terms of $p$-value, odds ratio (OR), and $95 \%$ confidence interval $(95 \% \mathrm{CI})$. The capability of the final model to predict CPBS at 3 months was assessed with a ROC Analysis and expressed as a ROC-AUC. Statistical analysis was performed using the R@ software version 3.5.1.

\section{Results}

Three hundred and fifty-three patients underwent breast surgery in the study period and were prospectively observed during the perioperative period. Of these, 46 (13\%) dropped out of the study because they were not contactable for assessment at 3 months follow-up; 307 patients were thus considered for the analysis (Fig. 1). Patients lost in the follow-up had demographic characteristics and comorbidities not statistically different than those considered for the final analysis.

The incidence of CPBS at 3 months was $28 \%$ [95\% CI 23.1-33.4\%] (median NRS 5 [3-7]). Table 1 displays patients' baseline characteristics, and surgical and anaesthesiologic factors. Most patients underwent mastectomy or breast conservation surgery, alone or in combination with other surgical procedures (e.g., cosmetic reconstruction and/or axillary surgery), as described in Table 1. All surgical procedures were performed under general anaesthesia alone (total intravenous or inhaled anaesthesia) or in association with other forms of regional anaesthesia (PECS block or local anaesthetics infiltration). A combination of morphine, ketorolac tromethamine, and paracetamol was used for analgesia at the end of surgery.

Drugs used for postoperative analgesia are shown in Table 2. About half of the patients were prescribed paracetamol $1 \mathrm{~g}$ or $500 \mathrm{mg}$ q.i.d. (according to the patient's weight) and morphine (administered with PCA set up to deliver a bolus of $1 \mathrm{mg}$ of morphine with a lockout interval of $15 \mathrm{~min}$ ). The remaining patients were prescribed paracetamol in combination with tramadol or ketorolac tromethamine as rescue analgesic. Static and dynamic NRS values in the CPBS and No-CPBS groups are shown in Table 3, as well as their parameters of association with CPBS at univariate analysis.

All variables statistically associated with CPBS with $p$ value $<0.2$ in the univariate analysis were considered for multivariate logistic regression analysis. In the final model, variables independently associated with CPBS were axillary surgery (sentinel node biopsy and/or axillary lymph node dissection) (OR [95\% CI], 2.99 [1.137.87], $p=0.03)$; preoperative use of pain medications (OR [95\% CI], 2.04 [1.20-3.46], $p=0.01$ ); and higher dynamic NRS values at $6 \mathrm{~h}$ postoperatively (OR [95\% CI], $1.28[1.05-1.55] p=0.01$ ). This model was able to identify the development of CPBS at 3 months postoperatively with a ROC-AUC of 0.67 (95\% CI [0.61-0.74]).

All pain intensity and interference scores measured through the BPI questionnaire are presented in Fig. 2. 


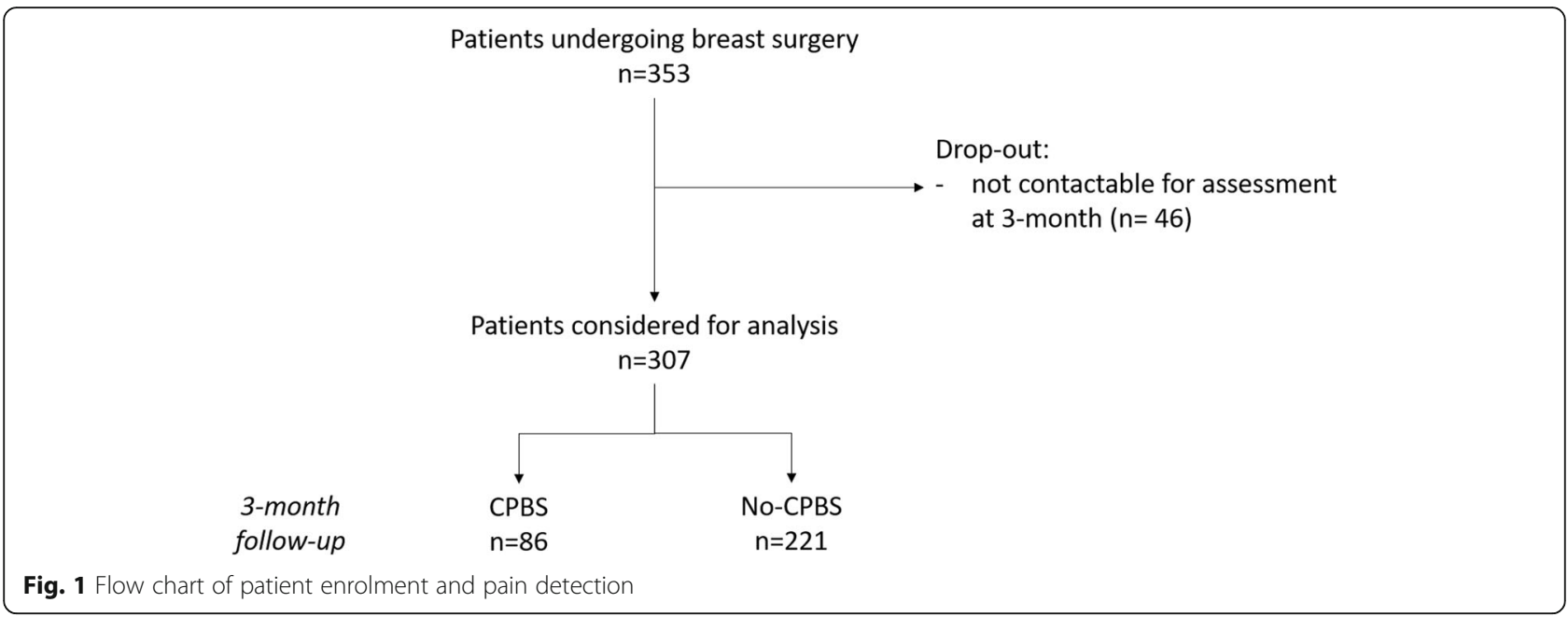

BPI scores at 3 months are also reported in the Supplementary Table 1.

\section{Discussion}

In this prospective, single centre, observational study performed in a large tertiary care teaching hospital, we have observed a $28 \%$ [95\% CI 23.1-33.4\%] incidence of CPBS in a cohort of female patients undergoing surgery for breast cancer. Axillary surgery, preoperative use of pain medications, and higher dynamic NRS values at $6 \mathrm{~h}$ postoperatively have been identified as independent predictors of CPBS.

Chronic pain is a very well-known complication of breast surgery (Alves Nogueira Fabro et al. 2012; De Oliveira et al. 2014; Tasmuth et al. 1996; Wang et al. 2018). Despite increasing recognition of chronic pain and the multidisciplinary efforts made to prevent this complication, the occurrence of persistent pain after breast surgery still remains high (Humble et al. 2018). The incidence of CPBS found in our cohort of patients (28\%) falls within the range of values reported in previous studies (i.e., 25-60\% (Gartner et al. 2009; Wang et al. 2018)). This wide variability in CPBS incidence mainly derives from the lack of a specific definition of CPBS, only recently provided by the IASP task force (Schug et al. 2019). The main significance of the present study lies in the fact that it provides estimates of the incidence of CPBS based on the IASP definition. Accordingly, in contrast with previous studies where CBPS was usually detected at 12-24 months postoperatively (Bell et al. 2014; Mejdahl et al. 2013), we have evaluated CPBS at 3 months follow-up. Furthermore, in order to avoid confounding factors or misinterpretation of signs or symptoms, each patient enrolled in this study was preoperatively taught how to correctly identify body areas (i.e., breast/anterolateral chest wall, axilla, ipsilateral arm) and symptoms of persisting postoperative pain, including neuropathic characteristics. Finally, follow-up assessment of pain at 3 months was carried out after the scheduled postoperative surgical and physiotherapy evaluations, so as to exclude other confounding causes of postoperative pain (e.g., seroma, hematoma, prosthesis infection, previous arm-shoulder pain). All these aspects have contributed to improve reliability of the estimated incidence of CPBS in our cohort of patients.

There is, however, no clear consensus about the definition of "high risk patients" for CPBS, thus making it difficult to identify those subjects who might benefit the most from careful, early pain assessment. A complex multidisciplinary, multiparametric approach involving also psychosocial and genetic factors has been suggested to perioperatively stratify patients and identify those at high risk of developing CPBS (Bortsov et al. 2020; James 2017). Nevertheless, because genotyping is expensive and usually unfeasible in routine clinical practice, strategies for risk stratification are currently based on the evaluation of those clinical and anamnestic, pre- and intraoperative predictors of CPBS that have already been identified in the literature. Given the observational nature of this study, it was not possible to explore genetic susceptibility in our cohort of patients. On the other hand, to the best of our knowledge, this is the first study evaluating selective pectoral muscle denervation as a potential risk factor for CPBS. Although denervation is a major risk factor for chronic neuropathic pain, none of the 19 patients undergoing selective pectoral muscle denervation for aesthetic purposes developed CPBS.

In contrast with previous studies, we have not observed an association between CPBS and patient age (Gartner et al. 2009; Vilholm et al. 2008), previous breast surgery (Vilholm et al. 2008), reconstructive surgery (Roth 2018), or implant-device placement (both above or below the pectoralis major muscle) (Wallace et al. 1996). Our study confirms that there is little evidence to 
Table 1 Patients' baseline characteristics, surgical, and anaesthesiologic factors in CPBS and No-CPBS groups

\begin{tabular}{|c|c|c|c|c|c|}
\hline & Total $(n=307)$ & No-CPBS $(n=221)$ & CPBS $(n=86)$ & OR $[95 \% \mathrm{Cl}]$ & $p$ \\
\hline \multicolumn{6}{|l|}{ Patient characteristics } \\
\hline Age (years) & $56.2 \pm 12.4$ & $55.3 \pm 12.4$ & $53.6 \pm 11.2$ & $0.99[0.97-1.01]$ & 0.275 \\
\hline Height (cm) & $163.5 \pm 6.3$ & $163.6 \pm 6.6$ & $163.4 \pm 5.3$ & $0.99[0.96-1.04]$ & 0.824 \\
\hline Weight (kg) & $64.5 \pm 12.5$ & $55.3 \pm 5.9$ & $55.2 \pm 4.8$ & 0.10 [0.99-1.03] & 0.212 \\
\hline BMI $\left(\mathrm{Kg} / \mathrm{m}^{2}\right)$ & $24.1 \pm 4.4$ & $23.9 \pm 4.1$ & $24.7 \pm 4.9$ & $1.04[0.98-1.10]$ & 0.168 \\
\hline Preoperative pain & 95 (30.9\%) & $56(25.3 \%)$ & $39(45.3 \%)$ & $1.13[0.64-1.97]$ & 0.686 \\
\hline Chronic use of pain drugs & $19(6.2 \%)$ & $9(4.1 \%)$ & $10(11.6 \%)$ & 3.10 [1.21-7.92] & 0.018 \\
\hline Anxiety/depression & 43 (14\%) & $33(14.9 \%)$ & $10(11.6 \%)$ & $0.75[0.35-1.60]$ & 0.446 \\
\hline Fibromyalgia & $2(0.7 \%)$ & $1(0.5 \%)$ & $1(1.2 \%)$ & $2.59[0.16-41.90]$ & 0.511 \\
\hline Neoadjuvant-CHT & $23(7.5 \%)$ & $15(6.8 \%)$ & $8(9.3 \%)$ & $1.41[0.58-3.45]$ & 0.461 \\
\hline Preop. hormone therapy & $37(12.1 \%)$ & $28(12.7 \%)$ & $9(10.5 \%)$ & $0.81[0.36-1.79]$ & 0.589 \\
\hline Neoadjuvant-RT & $1(0.33 \%)$ & $1(0.5 \%)$ & $0(0.0 \%)$ & - & - \\
\hline Previous ipsilateral breast surgery & $108(35.18 \%)$ & $78(35.3 \%)$ & 30 (34.9\%) & $0.98[0.58-1.66]$ & 1.000 \\
\hline School education & & & & & 0.517 \\
\hline Primary school & $30(9.77 \%)$ & $24(10.9 \%)$ & $6(7.0 \%)$ & $0.79[0.28-2.24]$ & \\
\hline Secondary school & $57(18.57 \%)$ & $40(18.1 \%)$ & $17(19.8 \%)$ & $1.35[0.62-2.93]$ & \\
\hline High school & $145(47.23 \%)$ & $100(45.2 \%)$ & $45(52.3 \%)$ & $1.42[0.75-2.69]$ & \\
\hline University & $75(24.43 \%)$ & $57(25.8 \%)$ & $18(20.9 \%)$ & Ref. & \\
\hline \multicolumn{6}{|l|}{ Surgical factors } \\
\hline Breast-conserving surgery & $149(48.5 \%)$ & $110(49.8 \%)$ & $39(45.3 \%)$ & $0.84[0.51-1.38]$ & 0.526 \\
\hline Mastectomy & $91(29.6 \%)$ & $61(27.6 \%)$ & $30(34.9 \%)$ & $1.41[0.83-2.39]$ & 0.214 \\
\hline $\begin{array}{l}\text { Implant-based reconstructive surgery (tissue-expanders } \\
\text { or prosthesis) }\end{array}$ & $113(36.8 \%)$ & $81(36.7 \%)$ & $32(37.2 \%)$ & $1.02[0.61-1.72]$ & 0.928 \\
\hline Pre-pectoral prosthesis & $23(7.5 \%)$ & $17(21.0 \%)$ & $6(18.8 \%)$ & Ref. & - \\
\hline Under-pectoral prosthesis or tissue-expander & $47(15.3 \%)$ & $32(39.5 \%)$ & 15 (46.9\%) & $1.33[0.44-4.05]$ & 0.618 \\
\hline Tissue-expander substitution with prosthesis & $43(14.0 \%)$ & $32(39.5 \%)$ & $11(34.4 \%)$ & $0.97[0.31-3.09]$ & 0.964 \\
\hline Axillary surgery & $146(47.6 \%)$ & $95(43.0 \%)$ & $51(59.3 \%)$ & $1.93[1.17-3.21]$ & 0.011 \\
\hline Sentinel node biopsy & 99 (32.3\%) & $64(29.0 \%)$ & $35(40.7 \%)$ & $0.94[0.46-1.96]$ & 0.877 \\
\hline Axillary lymph node dissection & $47(15.3 \%)$ & $31(14.0 \%)$ & $16(18.6 \%)$ & & \\
\hline Cosmetic surgery & $68(22.2 \%)$ & $48(21.7 \%)$ & $20(23.3 \%)$ & $1.09[0.60-1.98]$ & 0.762 \\
\hline Dorsal-flap reconstructive surgery & $1(0.3 \%)$ & $1(0.5 \%)$ & $0(0.0 \%)$ & - & - \\
\hline Bilateral surgery & $103(33.6 \%)$ & $70(31.8 \%)$ & $33(38.4 \%)$ & $1.33[0.79-2.24]$ & 0.276 \\
\hline Selective pectoral nerves dissection & $19(6.2 \%)$ & $12(5.5 \%)$ & 7 (8.1\%) & $1.53[0.58-4.02]$ & 0.390 \\
\hline \multicolumn{6}{|l|}{ Anaesthesiologic factors } \\
\hline Total intravenous anaesthesia & $251(81.8 \%)$ & $180(81.4 \%)$ & $71(82.6 \%)$ & $0.93[0.48-1.78]$ & 0.821 \\
\hline Propofol & $251(81.8 \%)$ & $180(81.4 \%)$ & $71(82.6 \%)$ & $1.08[0.56-2.07]$ & 0.821 \\
\hline Remifentanil & $221(72.0 \%)$ & $157(71.0 \%)$ & $64(74.4 \%)$ & $1.19[0.67-2.09]$ & 0.554 \\
\hline Sufentanil & $29(9.5 \%)$ & $22(10.0 \%)$ & 7 (8.1\%) & $0.80[0.33-1.95]$ & 0.626 \\
\hline Fentanil & $14(4.6 \%)$ & $9(4.1 \%)$ & $5(5.8 \%)$ & $1.45[0.47-4.47]$ & 0.513 \\
\hline Inhaled anaesthesia & $56(18.2 \%)$ & $41(18.6 \%)$ & $15(17.4 \%)$ & $1.07[0.56-2.07]$ & 0.999 \\
\hline Sevorane & $40(13 \%)$ & $29(13.1 \%)$ & $11(12.8 \%)$ & $0.88[0.23-3.32]$ & 0.846 \\
\hline Desflurane & $16(5.2 \%)$ & $12(5.4 \%)$ & $4(4.7 \%)$ & $1.14[0.30-4.29]$ & 0.846 \\
\hline Remifentanil & $32(10.4 \%)$ & $22(10.0 \%)$ & $10(11.6 \%)$ & $0.58[0.16-1.94]$ & 0.384 \\
\hline Fentanil & $24(7.8 \%)$ & $19(8.6 \%)$ & $5(5.8 \%)$ & $1.73[0.50-5.95]$ & 0.384 \\
\hline
\end{tabular}


Table 1 Patients' baseline characteristics, surgical, and anaesthesiologic factors in CPBS and No-CPBS groups (Continued)

\begin{tabular}{|c|c|c|c|c|c|}
\hline & Total $(n=307)$ & No-CPBS $(n=221)$ & CPBS $(n=86)$ & OR $[95 \% \mathrm{Cl}]$ & $p$ \\
\hline Regional anaesthesia & $66(21.5 \%)$ & $53(24.0 \%)$ & $13(15.1 \%)$ & $0.56[0.29-1.10]$ & 0.092 \\
\hline PECS 1 & $28(9.1 \%)$ & $22(10.0 \%)$ & $6(7.0 \%)$ & $0.68[0.27-1.74]$ & 0.418 \\
\hline PECS 2 & $17(5.6 \%)$ & $12(5.4 \%)$ & $5(5.8 \%)$ & $1.08[0.37-3.15]$ & 0.895 \\
\hline Local anaesthetics infiltration & $21(6.8 \%)$ & $19(8.6 \%)$ & $2(2.3 \%)$ & $0.25[0.03-1.09]$ & 0.075 \\
\hline \multicolumn{6}{|l|}{ Intraoperative analgesia } \\
\hline Paracetamol & $265(86.3 \%)$ & $188(85.1 \%)$ & 77 (89.5\%) & $1.50[0.69-3.29]$ & 0.309 \\
\hline Ketorolac & 49 (16.0\%) & $33(14.9 \%)$ & $16(18.6 \%)$ & $1.30[0.68-2.51]$ & 0.431 \\
\hline Morphine & $242(7.8 \%)$ & $169(76.5 \%)$ & $73(84.9 \%)$ & $1.73[0.89-3.37]$ & 0.108 \\
\hline
\end{tabular}

Among anaesthesiologic factors, specific drugs used for total intravenous anaesthesia and inhaled anaesthesia are described for both CPBS and No-CPBS groups. For patients treated with locoregional anaesthesia, use of pectoralis and serratus plane blocks (PECS1 and PECS2) and of local anaesthetics infiltration is reported. For variables with more than two levels, OR $[95 \% \mathrm{Cl}]$ are expressed with respect to the level used as reference (Ref.). Wald test $p$-values are 0.774 for implantbased reconstructive surgery and 0.517 for school education. Among patients who underwent axillary surgery, differences between those treated with sentinel node biopsy and those treated with axillary lymph node dissection were evaluated with a chi-squared test $(\mathrm{OR}[95 \% \mathrm{Cl}]=0.94[0.46-1.96], p$-value $=0.877)$

suggest CPBS might be influenced by type of anaesthesia (Cho et al. 2013; Steyaert et al. 2016; Veevaete and Lavand'homme 2014). However, it should be recognised that most $(81.8 \%)$ of the patients were treated with total intravenous anaesthesia thus making it difficult to reliably detect possible anaesthesia-related differences in CPBS. Similarly, the numbers of PECS blocks and local anaesthetics infiltration performed in this cohort are relatively small, thus potentially affecting our results. Although PECS block II has already been recognised as a protective factor for pain chronicisation (De Cassai et al. 2020), we have not observed this effect in our cohort. Furthermore, other techniques such as paravertebral blocks or epidural analgesia (Andreae and Andreae 2013) and other drugs such as ketamine or i.v. lidocaine (Crousier et al. 2008; Grigoras et al. 2012) known to have benefits in reducing chronic pain have not been used in this cohort of patients, and thus their role has not been explored in this study. The lack of information on the effects of locoregional anaesthesia and adjuvant analgesics in reducing CPBS should be recognised as a limitation of this study.

Independently associated factors predicting CPBS in our cohort of patients were long-term use of analgesics for pre-existing chronic pain, axillary surgery, and higher values of dynamic NRS at $6 \mathrm{~h}$ postoperatively.

Preoperative breast pain and/or pre-existing chronic pain before surgery are well-known risk factors for chronic postoperative pain, particularly for CPBS (Gartner et al. 2009; Wang et al. 2018). In this study, nearly a third of patients had preoperative pain, mainly low-back pain or migraine $(52.6 \%$ and $44.2 \%$ of cases respectively). Preoperative painful conditions seem to predispose patients to the development of chronic post-surgical pain/CPBS, probably because the postoperative transition from acute to chronic pain is facilitated by long-term central and peripheral pain sensitisation (Ji et al. 2018). In this study, preoperative chronic pain was not found to be an independent risk factor for CPBS, except for the most severe cases requiring chronic analgesic drugs for pain management. As far as we are aware, this is the first study reporting a correlation between the use of preoperative painkillers and CPBS. In our cohort of patients, migraine (treated with paracetamol and NSAIDs), low-back pain (treated with paracetamol, NSAIDs, and corticosteroids), and chronic dental pain (treated with NSAIDs and gabapentin) were the main causes for long-term use of analgesics. No patients had pre-existing breast or axillary pain.

The association between axillary surgery and CPBS has already been reported in the literature. In particular, conclusions produced from a meta-analysis study including more than 19,000 patients have highlighted a $21 \%$ increased risk of developing CPBS in those subjects who underwent axillary surgery (Wang et al. 2018). In this study, axillary surgery was associated with a $93 \%$ increased risk of developing CPBS. A likely explanation is the use of different follow-up time frames for evaluating the correlation between axillary surgery and CPBS. Among the studies evidencing a correlation between axillary lymph node dissection (ALND) and CPBS, three explored this correlation within 6 months postoperatively (Alves Nogueira Fabro et al. 2012; Karen et al. 2002; De Oliveira et al. 2014), and the remaining two within 12 months (Meretoja et al. 2014; Thornton et al. 2013). A higher likelihood of surgery-related nerve injury-more frequent during ALND than sentinel node biopsy-has been advocated as the most probable cause of this association. Interestingly, differences between sentinel node biopsy and ALND as risk factors for CPBS have not emerged in our cohort of patients, probably because of the low rate of ALND included in this study (15.3\% vs $>30 \%$ in other studies) (Wang et al. 2018). To the best of our knowledge, no study has so far evaluated the possible role of sentinel node biopsy as a risk factor for CPBS. Furthermore, it should be underlined that, beside the effects of single surgical procedures (as reported 
Table 2 Analgesics used postoperatively

\begin{tabular}{|c|c|c|c|c|c|}
\hline & Total $(n=307)$ & No-CPBS $(n=221)$ & CPBS $(n=86)$ & OR $[95 \% \mathrm{Cl}]$ & $p$ \\
\hline \multicolumn{6}{|c|}{ Prescribed for postoperative analgesia } \\
\hline Paracetamol & $307(100 \%)$ & $221(100 \%)$ & $86(100 \%)$ & - & - \\
\hline Morphine (PCA) & $142(46.3 \%)$ & $101(45.7 \%)$ & $41(47.7 \%)$ & $1.08[0.64-1.84]$ & 0.799 \\
\hline Tramadol rescue & 95 (30.9\%) & $62(28.1 \%)$ & $33(38.8 \%)$ & $1.62[0.93-2.84]$ & 0.074 \\
\hline Ketorolac rescue & $70(22.8 \%)$ & $54(24.4 \%)$ & $16(21.1 \%)$ & $0.83[0.41-1.60]$ & 0.639 \\
\hline \multicolumn{6}{|c|}{ Actually administered for postoperative analgesia } \\
\hline At $3 \mathrm{~h}$ & Total $(n=307)$ & No-CPBS $(n=221)$ & CPBS $(n=86)$ & & \\
\hline Currently using PCA & $142 / 142(100 \%)$ & $101 / 101(100 \%)$ & $41 / 41(100 \%)$ & & \\
\hline Doses requested & $1[0,21]$ & $0[0,21]$ & $1[0,9]$ & $1.05[0.91-1.21]$ & 0.472 \\
\hline Doses administered & $1[1,6]$ & $0[0,6]$ & $1[0,5]$ & 1.05 [0.79-1.39] & 0.751 \\
\hline Tramadol rescue & 4/95 (4.2\%) & $3 / 62(4.8 \%)$ & 1/33 (3.0\%) & 0.67 [0.07-6.72] & 0.731 \\
\hline Ketorolac rescue & $3 / 70(4.3 \%)$ & $3 / 54(5.6 \%)$ & $0 / 16(0 \%)$ & - & - \\
\hline At $6 \mathrm{~h}$ & Total $(n=292)$ & No-CPBS $(n=208)$ & CPBS $(n=84)$ & & \\
\hline Currently using PCA & 139/142 (97.9\%) & 99/101 (98.0\%) & 40/41 (97.6\%) & & \\
\hline Doses requested & $1[0,26]$ & $1[0,26]$ & $1.50[0,15]$ & 1.08 [0.98-1.18] & 0.133 \\
\hline Doses administered & $1[0,11]$ & $1[0,11]$ & $2[0,10]$ & 1.16 [0.98-1.36] & 0.078 \\
\hline Tramadol rescue & $1 / 81(1.2 \%)$ & $0(0 \%)$ & $1 / 26(3.8 \%)$ & - & - \\
\hline Ketorolac rescue & $1 / 57(1.8 \%)$ & $1 / 46(2.2 \%)$ & $0(0 \%)$ & - & - \\
\hline At $12 \mathrm{~h}$ & Total $(n=254)$ & No-CPBS $(n=180)$ & CPBS $(n=74)$ & & \\
\hline Currently using PCA & 106/142 (74.7\%) & 76/101 (75.2\%) & 30/41 (73.2\%) & & \\
\hline Doses requested & $2[0,28]$ & $2[0,28]$ & $4[0,25]$ & 1.06 [0.99-1.14] & 0.119 \\
\hline Doses administered & $2[0,14]$ & $2[0,13]$ & $3.50[0,14]$ & $1.11[0.98-1.25]$ & 0.097 \\
\hline Tramadol rescue & 2/69 (2.9\%) & $1 / 46(2.2 \%)$ & $1 / 23(4.3 \%)$ & $2.05[0.12-34.3]$ & 0.619 \\
\hline Ketorolac rescue & $5 / 54(9.3 \%)$ & $4 / 44(9.1 \%)$ & $1 / 10(10.0 \%)$ & $1.11[0.11-11.2]$ & 0.929 \\
\hline At $24 \mathrm{~h}$ & & No-CPBS $(n=111)$ & CPBS $(n=45)$ & & \\
\hline Currently using PCA & 47/110 (42.7\%) & $32 / 79$ (40.5\%) & 15/31 (48.4\%) & & \\
\hline Doses requested & $3[0,35]$ & $3[0,23]$ & $4[1,35]$ & $1.05[0.96-1.15]$ & 0.298 \\
\hline Doses administered & $3[0,17]$ & $3[0,17]$ & $4[1,14]$ & $1.06[0.91-1.24]$ & 0.292 \\
\hline Tramadol rescue & 0/26 (0\%) & $0(0 \%)$ & $0(0 \%)$ & - & - \\
\hline Ketorolac rescue & 2/33 (6.1\%) & $2 / 27(7.4 \%)$ & $0(0 \%)$ & - & - \\
\hline At $48 \mathrm{~h}$ & & No-CBPS $(n=35)$ & CPBS $(n=23)$ & & \\
\hline Currently using PCA & 4/142 (2.82\%) & $1 / 24(4.2 \%)$ & 3/17 (17.6\%) & & \\
\hline Doses requested & $12[4,13]$ & 11 & $13[4,13]$ & $0.92[0.47-1.82]$ & 0.817 \\
\hline Doses administered & $6.5[4,11]$ & 11 & $4[4,9]$ & - & - \\
\hline Tramadol rescue & 0/8 (0\%) & $0(0 \%)$ & $0(0 \%)$ & - & - \\
\hline Ketorolac rescue & 1/9 (11.1\%) & $0(0 \%)$ & $1(100 \%)$ & - & - \\
\hline
\end{tabular}

At the different time points, the percentages of patients on the surgical ward using PCA and/or tramadol and ketorolac tromethamine as prescribed rescue analgesics are reported over time. Requested and administered doses are expressed as median and minimum-maximum values. Among patients treated with PCA in the No-CPBS and CPBS groups, those receiving less than 3 doses (1 dose = morphine $1 \mathrm{mg}$ ) were respectively 94 (93.1\%) and 40 (97.6\%) in the first $3 \mathrm{~h}$ postoperatively and $84(84.8 \%)$ and $31(77.5 \%)$ in the first $6 \mathrm{~h}$ postoperatively; those receiving less than 6 doses in the first $12 \mathrm{~h}$ postoperatively were 67 ( $88.2 \%)$ and $26(86.7 \%)$, respectively; those receiving less than 10 doses in the first $24 \mathrm{~h}$ were $28(87.5 \%)$ and 14 (93.3\%), respectively; those receiving less than 15 doses in the first $48 \mathrm{~h}$ postoperatively were $1(100 \%)$ and $3(100 \%)$, respectively

in Table 1), the combination of different procedures might also have a synergic/additive role in determining CPBS. This issue has not been explored in this study.
Higher dynamic NRS values at $6 \mathrm{~h}$ postoperatively play a role as independent factors to predict CPBS in our cohort of patients. Several studies have recognised 
Table 3 Static and dynamic postoperative NRS in both CPBS and No-CPBS groups. Numeric rating scale (NRS) values are expressed as median and IQR

\begin{tabular}{|c|c|c|c|c|c|}
\hline Pain intensity & Total $(n=307)$ & No-CPBS $(n=221)$ & CPBS $(n=86)$ & OR [95\% Cl] & $p$ \\
\hline \multicolumn{6}{|l|}{ At $0 \mathrm{~h}$} \\
\hline NRS at rest & $1[0,9]$ & $1[0,9]$ & $1[0,8]$ & $1.13[1.00-1.28]$ & 0.075 \\
\hline NRS during movement & $1[0,10]$ & $1[0,10]$ & $2[0,9]$ & $1.12[1.01-1.25]$ & 0.051 \\
\hline At $3 \mathrm{~h}$ & Total $(n=306)$ & No CPBS $(n=220)$ & CPBS $(n=86)$ & & \\
\hline NRS at rest & $1[0,7]$ & $1[0,5]$ & $1[0,7]$ & $1.28[1.02-1.62]$ & 0.034 \\
\hline NRS during movement & $2[1,8]$ & $2[0,6]$ & $2[0,8]$ & 1.31 [1.08-1.59] & 0.004 \\
\hline At $6 \mathrm{~h}$ & Total $(n=292)$ & No CPBS $(n=208)$ & CPBS $(n=84)$ & & \\
\hline NRS at rest & $1[0,5]$ & $1[0,5]$ & $1[0,5]$ & $1.24[0.98-1.56]$ & 0.101 \\
\hline NRS during movement & $2[1,7]$ & $2[0,5]$ & $2[0,7]$ & $1.27[1.06-1.54]$ & 0.041 \\
\hline At $12 \mathrm{~h}$ & Total $(n=254)$ & No CPBS $(n=180)$ & CPBS $(n=74)$ & & \\
\hline NRS at rest & $1[0,6]$ & $1[0,6]$ & $1[0,5]$ & $1.26[0.99-1.58]$ & 0.036 \\
\hline NRS during movement & $2[0,7]$ & $2[0,6]$ & $2[0,7]$ & $1.24[1.04-1.48]$ & 0.024 \\
\hline At $24 \mathrm{~h}$ & Total $(n=156)$ & No CPBS $(n=111)$ & CPBS $(n=45)$ & & \\
\hline NRS at rest & $1[0,5]$ & $1[0,4]$ & $1[0,5]$ & $1.36[0.98-1.90]$ & 0.110 \\
\hline NRS during movement & $2[0,6]$ & $1[0,5]$ & $2[0,6]$ & $1.35[1.06-1.71]$ & 0.024 \\
\hline At $48 \mathrm{~h}$ & Total $(n=58)$ & No CPBS $(n=35)$ & CPBS $(n=23)$ & & \\
\hline NRS at rest & $1[0,4]$ & $1[0,4]$ & $1[0,2]$ & $0.86[0.47-1.56]$ & 0.817 \\
\hline NRS during movement & $2[0,6]$ & $2[0,5]$ & $2[0,6]$ & $1.26[0.90-1.75]$ & 0.279 \\
\hline
\end{tabular}

presence and severity of acute postoperative pain as risk factors for postoperative chronic pain (Palotie et al. 2013; Tasmuth et al. 1996), particularly for CPBS (Fassoulaki et al. 2009). Our results suggest that one-point increase in dynamic NRS values corresponds to a $27 \%$ increased risk of developing CPBS. Median postoperative NRS values reported in this study, both at rest and during movement, suggest that adequate postoperative management of pain was generally achieved in the enrolled population. It is worth noting that patients who developed CPBS at 3 months exhibited higher NRS values than those who did not. In particular, statistically significant differences were observed at univariate analysis between CPBS and No-CPBS groups in terms of dynamic and static NRS values at $3 \mathrm{~h}, 6 \mathrm{~h}, 12 \mathrm{~h}$, and $24 \mathrm{~h}$ postoperatively.

Pain intensity and pain interference with daily functions were assessed through the Italian validated version of the BPI questionnaire. This is a reliable, multidimensional tool for evaluating also non-oncological chronic pain and has already been used for CPBS (Bonezzi et al. 2002; De Oliveira et al. 2014). Analysis of BPI scores by item showed that chronic pain was of mild, moderate, and severe intensity in $96.5,2.3$, and $1.2 \%$ of cases, respectively. In 18 (20.9\%) patients with CPBS, the median NRS values recorded during movement were greater than five, therefore reflecting moderate to severe chronic pain. These results are in line with those reported in the literature (Andersen and Kehlet 2013; Leysen et al. 2018; Peuckmann et al. 2009). Finally, according to the BPI questionnaire, CPBS had a profound impact on sleep quality, mood, and perception of happiness.

It is plausible that a number of limitations may have influenced the results of this study. First, this is a singlecentre study carried out in a single teaching hospital. Second, our cohort of patients was quite small and therefore our findings need to be validated in a larger population. Also, the numbers of PECS blocks and local anaesthetics infiltration performed in our cohort of patients were too small to adequately address the impact of these procedures on CPBS. Third, we were not able to evaluate other factors such as psychological or genetic features as potential predictors of CPBS. A further limitation is that neither the numbers and levels of sentinel node biopsy nor the preservation vs cut of the intercostobrachial nerve were recorded. Also, we did not explore the effects of the combination of different surgical procedures in determining CPBS. Finally, we were not able to evaluate the effects of locoregional anaesthesia and adjuvant analgesics as well as the role of acupuncture and other non-pharmacologic analgesic therapies or interventional procedures in modulating CPBS.

\section{Conclusions}

Chronic pain after breast surgery is a frequent complication that interferes with patients' daily activities. In this 


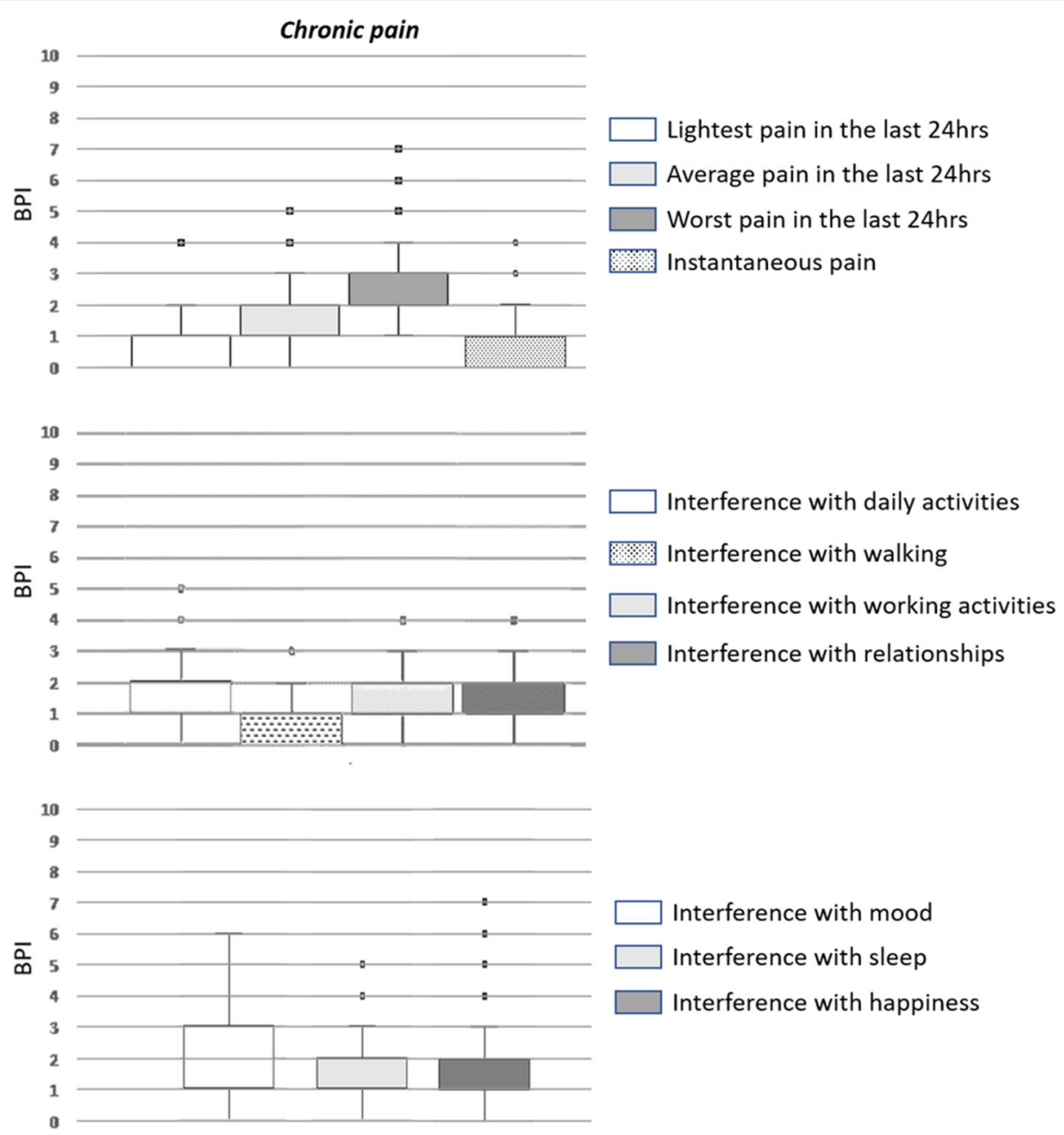

Fig. 2 Intensity and impact of pain on patients' quality of life as from the BPI questionnaire

study, evaluation of CPBS according to the IASP definition resulted in a $28 \%$ incidence at 3 months postoperatively. The possibility to early detect persistent pain, particularly in those patients at high-risk for CPBS, might help physicians to more effectively prevent pain chronicisation. In our cohort of adult surgical female patients, long-term use of analgesics for pre-existing chronic pain, axillary surgery, and higher dynamic NRS values at $6 \mathrm{~h}$ postoperatively were statistically associated with a higher risk of developing CPBS. A timely identification of high-risk patients might allow the implementation of proactive pharmacologic and non-pharmacologic approaches to prevent CPBS.

\section{Supplementary Information}

The online version contains supplementary material available at https://doi. org/10.1186/s13741-021-00176-6.

Additional file 1: Table S1. BPI score in patients with pain at 3 months.

\section{Abbreviations}

CPBS: Chronic pain after breast surgery; IASP: International Association for the Study of Pain; NRS: Numerical rating scale; BPI: Brief Pain Inventory; PCA: Patient-controlled analgesia; ALND: Axillary lymph node dissection

\section{Acknowledgements}

We would like to acknowledge Dr. Vittorio Bocciero for technical and organisational support.

\section{Authors' contributions}

G.V.: This author was responsible for all aspects of the study thereby ensuring that questions related to the accuracy or integrity of any part of the work were appropriately investigated and resolved; R.M.: This author helped with analysis and interpretation of data; C.S.C.: This author helped with analysis and interpretation of data; V.R.: This author substantially contribute to study conception and design, acquisition of data, and analysis and interpretation of data; M.D.D.: This author substantially contributed to study conception and design, acquisition of data, and analysis and interpretation of data; D.P.M.: This author substantially contributed to study conception and design, acquisition of data, and analysis and interpretation of data; L.P.: This author substantially contributed to study conception and design, acquisition of data, and analysis and interpretation of data; A.R.D.G. This author contributed to draft the manuscript and review it critically; S.R:: This author substantially contributed to study conception and design, and approved the final version of the manuscript. 


\section{Funding}

Authors disclose that Fondazione Cassa di Risparmio di Firenze (grant number 2014.0679) and "Philip and Irene Toll Gage Foundation" (grant number: NA) have supported this study through research grants aimed at study coordination, statistical analysis, and recruitment of investigators. The funders had no role in study design, data collection and analysis, decision to publish, or preparation of the manuscript.

\section{Availability of data and materials}

The datasets analysed during the current study are available from the corresponding author on reasonable request.

\section{Ethics approval and consent to participate}

The institutional review boards of the centre ("Comitato Etico Area Vasta Toscana Centro") reviewed and approved the study protocol for the Azienda Ospedaliero Universitaria Careggi in Florence (OSS.16.246). Because of the retrospective nature of this study, written consent for analysis and publication of clinical data was waived from the IRB. All methods of consent were approved by the appropriate ethics committees.

\section{Consent for publication}

Not applicable.

\section{Competing interests}

Dr. Gianluca Villa has received honoraria for lectures from Baxter and Pall Italia. Prof. Stefano Romagnoli has received honoraria for lectures/ consultancy from Baxter, Orion Pharma, Vygon, MSD, and Medtronic and funds for travel expenses, hotel accommodation, and registration to meetings from Baxter, BBraun, Pall International, Medigas, and Vygon. Prof. Angelo Raffaele De Gaudio has received research grants from MSD Italia, Baxter, and Pall International. The remaining authors disclose that they do not have any potential conflict of interest.

Received: 3 August 2020 Accepted: 31 January 2021

Published online: 24 February 2021

\section{References}

Alves Nogueira Fabro E, Bergmann A, do Amaral e Silva B, Padula Ribeiro AC, de Souza Abrahão K, da Costa Leite Ferreira MG, et al. Post-mastectomy pain syndrome: incidence and risks. Breast. Elsevier Ltd. 2012;21(3):321-5.

Andersen KG, Kehlet $\mathrm{H}$. Persistent pain after breast cancer treatment. Pain Women. 2013;1(3):186-97.

Andreae MH, Andreae DA. Regional anaesthesia to prevent chronic pain after surgery: a Cochrane systematic review and meta-analysis. Br J Anaesth. 2013; 111(5):711-20.

Belfer I, Schreiber KL, Shaffer JR, Shnol H, Blaney K, Morando A, et al. Persistent postmastectomy pain in breast cancer survivors: analysis of clinical, demographic, and psychosocial factors. J Pain. Elsevier Ltd. 2013;14(10):1185-95.

Bell RJ, Robinson PJ, Nazeem F, Panjari M, Fradkin P, Schwarz M, et al. Persistent breast pain 5 years after treatment of invasive breast cancer is largely unexplained by factors associated with treatment. J Cancer Surviv. 2014;8(1): $1-8$.

Bonezzi C, Nava A, Barbieri M, Bettaglio R, Demartini L, Miotti D, et al. Validazione della versione italiana del brief pain inventory nei pazienti con dolore cronico. Minerva Anestesiol. 2002;68(7-8):607-11.

Bortsov AV, Devor M, Kaunisto MA, Kalso E, Brufsky A, Kehlet H, et al. CACNG2 polymorphisms associate with chronic pain following mastectomy. Pain. 2020;160(3):561-8.

Brummett CM. Chronic pain following breast surgery. Tech Reg Anesth Pain Manag. Elsevier Inc. 2011;15(3):124-32.

Caffo O, Amichetti M, Ferro A, Lucenti A, Valduga F, Galligioni E. Pain and quality of life after surgery for breast cancer. Breast Cancer Res Treat. 2003;80(1):39-48.

De Cassai A, Bonanno C, Andreatta G, Marchet A, Barbieri S, Feltracco P, et al. PECS II may reduce chronic pain after breast surgery: a propensity score based secondary analysis of the BREAST trial. J Clin Anesth. Elsevier. 2020;64: 109851. https://doi.org/10.1016/j.jclinane.2020.109851.

Cho AR, Kwon JY, Kim KH, Lee HJ, Kim HK, Kim ES, et al. The effects of anesthetics on chronic pain after breast cancer surgery. Anesth Analg. 2013; 116(3):685-93.
Crousier M, Cognet V, Khaled M, Gueugniaud PY, Piriou V. Effet de la kétamine dans la prévention des douleurs chroniques post-mastectomies. Étude Pilote Ann Fr Anesth Reanim. 2008;27(12):987-93.

Daut RL, Cleeland CS, Flanery RC. Development of the Wisconsin brief pain questionnaire to assess pain in cancer and other diseases. Pain. 1983;17(2): 197-210.

Deumens R, Steyaert A, Forget P, Schubert M, Lavand'homme P, Hermans E, et al. Prevention of chronic postoperative pain: cellular, molecular, and clinical insights for mechanism-based treatment approaches. Prog Neurobiol. England. 2013;104:1-37.

Fassoulaki A, Triga A, Sarantopoulos C, Staikou C, Melemeni A. Acute postoperative pain predicts chronic pain after breast surgery for cancer. Eur J Anaesthesiol. 2009;24(Supplement 39):174-5.

Gartner R, Jensen MB, Nielsen J, Ewertz M, Kroman N, Kehlet H. Prevalence of and factors associated with persistent pain following breast cancer surgery. [erratum appears in JAMA. 2012 Nov 21;308(19):1973]. JAMA. 2009;302(18): 1985-92.

Grigoras A, Lee P, Sattar F, Shorten G. Perioperative intravenous lidocaine decreases the incidence of persistent pain after breast surgery. Clin J Pain. 2012;28(7):567-72.

Hamood R, Hamood H, Merhasin I, Keinan-Boker L. Chronic pain and other symptoms among breast cancer survivors: prevalence, predictors, and effects on quality of life. Breast Cancer Res Treat. Springer US. 2018;167(1):157-69.

Humble SR, Varela N, Jayaweera A, Bhaskar A. Chronic postsurgical pain and cancer. Curr Opin Support Palliat Care. 2018;12(2):118-23.

James SK. Chronic postsurgical pain: is there a possible genetic link? Br J Pain. 2017;11(4):178-85.

Ji R, Nackley A, Huh Y, Terrando NMW. Neuroinflammation and central sensitization in chronic and generalized pain. Anestesiología. 2018;19(2):34366.

Jung BF, Ahrendt GM, Oaklander AL, Dworkin RH. Neuropathic pain following breast cancer surgery: proposed classification and research update. Pain. 2003;104(1):1-13.

Karen KS, Mary JN, Carolyn C, Lindsey S, Martin WL, Todd MT. Comparison of side effects between sentinel lymph node and axillary lymph node dissection for breast cancer. Ann Surg Oncol. 2002;9(8):745-53.

Lavand'homme P. Transition from acute to chronic pain after surgery. Pain. 2017; 158(4):S50-4

Leysen L, Adriaenssens N, Nijs J, Pas R, Bilterys T, Vermeir S, et al. Chronic pain in breast cancer survivors: nociceptive, neuropathic, or central sensitization pain? Pain Pract. 2018;19:1-13.

Mejdahl MK, Andersen KG, Gärtner R, Kroman N, Kehlet H. Persistent pain and sensory disturbances after treatment for breast cancer: six year nationwide follow-up study. BMJ. 2013;346(7907):1-14.

Meretoja TJ, Leidenius MHK, Tasmuth T, Sipilä R, Kalso E. Pain at 12 months after surgery for breast cancer. JAMA. 2014;311(1):90-2.

Miaskowski C, Cooper B, Paul SM, West C, Langford D, Levine JD, et al. Identification of patient subgroups and risk factors for persistent breast pain following breast cancer surgery. J Pain. Elsevier Ltd. 2012;13(12):1172-87.

Odle TG. Adverse effects of breast cancer treatment. Radiol Technol. 2014;85(3): 297-319.

De Oliveira GS, Chang R, Khan SA, Hansen NM, Khan JH, McCarthy RJ, et al. Factors associated with the development of chronic pain after surgery for breast cancer: a prospective cohort from a tertiary center in the United States. Breast J. 2014;20(1):9-14.

Palotie A, Kaunisto MA, Tikkanen E, Jokela R, Sipilä R, Kalso EA, et al. Pain in 1,000 women treated for breast cancer. Anesthesiology. 2013;119(6):1410-21.

Peuckmann V, Ekholm O, Rasmussen NK, Groenvold M, Christiansen P, Møller S, et al. Chronic pain and other sequelae in long-term breast cancer survivors: nationwide survey in Denmark. Eur J Pain. 2009;13(5):478-85.

Poleshuck EL, Katz J, Andrus CH, Hogan LA, Jung BF, Kulick DI, et al. Risk factors for chronic pain following breast cancer surgery: a prospective study. J Pain. 2006; $7(9): 626-34$.

Roth RS. Chronic postsurgical pain following breast reconstruction: a commentary and critique. Breast Cancer Res Treat. Springer US. 2018;169(2): 209-16.

Sarhadi NS, Shaw Dunn J, Lee FD, Soutar DS. An anatomical study of the nerve supply of the breast, including the nipple and areola. Br J Plast Surg. England. 1996;49(3):156-64.

Schou Bredal I, Smeby NA, Ottesen S, Warncke T, Schlichting E. Chronic pain in breast cancer survivors: comparison of psychosocial, surgical, and medical 
characteristics between survivors with and without pain. J Pain Symptom Manag. Elsevier Inc. 2014;48(5):852-62.

Schug SA, Lavand'Homme P, Barke A, Korwisi B, Rief W, Treede RD. The IASP classification of chronic pain for ICD-11: chronic postsurgical or posttraumatic pain. Pain. 2019;160(1):45-52.

Spivey TL, Gutowski ED, Zinboonyahgoon N, King TA, Dominici L, Edwards RR, et al. Chronic pain after breast surgery: a prospective, observational study. Ann Surg Oncol. Springer International Publishing. 2018;25(10):2917-24.

Steyaert A, Forget P, Dubois V, Lavand'homme P, De Kock M. Does the perioperative analgesic/anesthetic regimen influence the prevalence of longterm chronic pain after mastectomy. J Clin Anesth. Elsevier B.V. 2016;33:20-5.

Tasmuth T, Von Smitten K, Kalso E. Pain and other symptoms during the first year after radical and conservative surgery for breast cancer. Br J Cancer. 1996; 74(12):2024-31

Thornton AJ, Powell R, Heys SD, Thompson AM, Wells M, Scott NW, et al. Psychological, surgical, and sociodemographic predictors of pain outcomes after breast cancer surgery: a population-based cohort study. Pain. International Association for the Study of Pain. 2013;155(2):232-43.

Urits I, Lavin C, Patel M, Maganty N, Jacobson X, Ngo AL, et al. Chronic pain following cosmetic breast surgery: a comprehensive review. Pain Ther. Springer Healthcare. 2020;9(1):71-82. https://doi.org/10.1007/s40122-020-001 50-y.

Veevaete L, Lavand'homme P. Opioid-induced hyperalgesia: new insights into the chronicization of pain. Tech. Reg. Anesth. Pain Manag. Elsevier. 2014; 18(3):100-4.

Vilholm OJ, Cold S, Rasmussen L, Sindrup SH. The postmastectomy pain syndrome: an epidemiological study on the prevalence of chronic pain after surgery for breast cancer. Br J Cancer. 2008;99(4):604-10.

Wallace MS, Wallace AM, Lee J, Dobke MK. Pain after breast surgery: a survey of 282 women. Pain. 1996;66(2-3):195-205.

Wang L, Hong BY, Kennedy SA, Chang Y, Hong CJ, Craigie S, et al. Predictors of unemployment after breast cancer surgery: a systematic review and metaanalysis of observational studies. J Clin Oncol. 2018;36(18):1868-79.

\section{Publisher's Note}

Springer Nature remains neutral with regard to jurisdictional claims in published maps and institutional affiliations.

Ready to submit your research? Choose BMC and benefit from:

- fast, convenient online submission

- thorough peer review by experienced researchers in your field

- rapid publication on acceptance

- support for research data, including large and complex data types

- gold Open Access which fosters wider collaboration and increased citations

- maximum visibility for your research: over $100 \mathrm{M}$ website views per year

At $\mathrm{BMC}$, research is always in progress.

Learn more biomedcentral.com/submissions 